\title{
Systematic review of the cost-effectiveness of transcatheter aortic valve implantation
}

\author{
Praveen Indraratna, MBBS, ${ }^{\mathrm{a}, \mathrm{b}} \mathrm{Su}$ C. Ang, MBBS, ${ }^{\mathrm{a}, \mathrm{b}}$ Hemal Gada, MD, ${ }^{\mathrm{a}}$ Tristan D. Yan, MBBS, PhD, ${ }^{\mathrm{a}, \mathrm{c}}$ \\ Con Manganas, MBBS, ${ }^{\mathrm{b}}$ Paul Bannon, MBBS, PhD, ${ }^{\mathrm{a}, \mathrm{c}}$ and Christopher Cao, MBBS, BSc (Med) ${ }^{\mathrm{a}, \mathrm{b}}$
}

\begin{abstract}
Objective: Transcatheter aortic valve implantation (TAVI) has emerged as an alternative treatment to aortic valve replacement (AVR) for selected patients with severe aortic stenosis. The present systematic review was conducted to analyze the cost-effectiveness of this novel technique within reimbursed healthcare systems.
\end{abstract}

\begin{abstract}
Methods: Two reviewers used 7 electronic databases from January 2000 to November 2012 to identify relevant cost-effectiveness studies of TAVI versus AVR or medical therapy. The primary endpoints were the incremental cost-effectiveness ratio (ICER) and the probability of cost-effectiveness. The eligible studies for the present systematic review included those in which the cost-effectiveness data were measured or projected for TAVI and either medical therapy or AVR. All forms of TAVI were included, and all retrieved publications were limited to the English language.
\end{abstract}

Results: Eight studies were included for quantitative assessment. The ICER for TAVI compared with medical therapy for surgically inoperable patients ranged from US\$26,302 to US\$61,889 per quality-adjusted life year gained. The probability of TAVI being cost-effective compared with medical therapy ranged from 0.03 to 1.00 . The ICER values for TAVI compared with AVR for high-risk surgical candidates ranged from US\$32,000 to US $\$ 975,697$ per quality-adjusted life year gained. The probability of TAVI being cost-effective in this cohort ranged from 0.116 to 0.709 .

Conclusions: Depending on the ICER threshold selected, TAVI is potentially justified on both medical and economic grounds compared with medical therapy for patients deemed to be surgically inoperable. However, in the high-risk surgical patient cohort, the evidence is currently insufficient to economically justify the use of TAVI in preference to AVR. (J Thorac Cardiovasc Surg 2014;148:509-14)

Aortic stenosis (AS) is the most common form of valvular heart disease in developed nations, with a reported 12 -month mortality rate of $>30 \%$ for medically treated symptomatic patients. ${ }^{1}$ Surgical aortic valve replacement (AVR) has long been the accepted standard of care for patients with symptomatic AS. However, the emergence of transcatheter aortic valve implantation (TAVI), using either a percutaneous or transapical approach, has provided an alternative therapeutic option for selected patients. ${ }^{2}$ Although TAVI has demonstrated superior survival and symptomatic outcomes for inoperable patients compared with medical therapy in the Placement of Aortic Transcatheter Valve (PARTNER) B trial, the evidence assessing its role in high-risk operable surgical candidates remains controversial. ${ }^{2,3}$

\footnotetext{
From the Systematic Review Unit, ${ }^{\mathrm{a}}$ Collaborative Research (CORE) Group, Macquarie University, Sydney, Australia; Department of Cardiothoracic Surgery, ${ }^{\text {b }}$ St George Hospital, Sydney, Australia; and Department of Cardiothoracic Surgery, ${ }^{\mathrm{c}}$ Royal Prince Alfred Hospital, University of Sydney, Sydney, Australia. Disclosures: Authors have nothing to disclose with regard to commercial support. Received for publication June 13, 2013; revisions received Aug 25, 2013; accepted for publication Oct 13, 2013; available ahead of print Nov 25, 2013.

Address for reprints: Christopher Cao, MBBS, BSc (Med), Systematic Review Unit, Collaborative Research (CORE) Group, Department of Cardiothoracic Surgery, St George Hospital, Sydney, Australia (E-mail: drchriscao@gmail.com). $0022-5223 / \$ 36.00$

Copyright (C) 2014 by The American Association for Thoracic Surgery http://dx.doi.org/10.1016/j.jtcvs.2013.10.023
}

Establishing the cost-effectiveness of a new therapy using standardized metrics is essential before its widespread use in reimbursed healthcare systems. The evaluation of the cost-effectiveness of a procedure relies on the estimation of inputs, including the costs and clinical outcomes experienced by patients. This can be achieved using a trial-based or model-based approach. Typically, cost-effectiveness measurements such as the incremental cost-effectiveness ratio (ICER) will be calculated and compared with national thresholds of economic efficiency, with sensitivity analyses performed to examine the probability of the procedure remaining or becoming costeffective after input parameter modification.

Despite an exponential growth in the performance of TAVI in many European and North American centers, a paucity of robust clinical data remains to assess the cost-effectiveness of this relatively novel technique. The present systematic review aimed to assess TAVI compared with AVR and medical therapy for patients with severe AS using ICER and the probability of cost-effectiveness as the primary endpoints.

\section{METHODS}

\section{Data Search Strategy}

Electronic data searches were performed using Ovid Medline, PubMed, EMBASE, National Health Service Economic Evaluation Database, 


\section{Abbreviations and Acronyms}

AS = aortic stenosis

AVR = aortic valve replacement

ICER = incremental cost-effectiveness ratio

PARTNER $=$ Placement of Aortic Transcatheter Valve

QALY = quality-adjusted life year

TAVI $=$ transcatheter aortic valve implantation

WTPT = willingness-to-pay threshold

American College of Physicians Journal Club, Database of Abstracts of Review of Effects, and Cochrane Database of Systematic Reviews from January 2000 to November 2012. To maximize the sensitivity of the search, we combined the terms "transcatheter" or "transapical" or "transfemoral" or "transcutaneous" or "transvascular" or "percutaneous" with "aortic valve" or "aortic valve stenosis" or "TAVI" or "transcatheter aortic valve implantation" or "transcatheter aortic valve replacement" and "economics" or "cost" or "cost-utility" or "cost-effectiveness" or "cost-benefit analysis" as either key words or MeSH terms. After an initial screening of the titles and abstracts, the full text of the potentially relevant studies was obtained for additional evaluation. The reference lists of all retrieved studies were reviewed for identification of additional relevant studies.

\section{Selection Criteria}

The eligible studies for the present systematic review included those in which the cost-effectiveness data were measured or projected for TAVI and either medical therapy or AVR. All forms of TAVI were included, regardless of the anatomic approach or type of valve used. All publications retrieved were limited to those in the English language. Abstracts, case reports, editorials, letters, conference presentations, and expert opinions were excluded.

\section{Data Extraction and Critical Appraisal}

All data were extracted from the article text, tables, and figures. Two investigators (P.I. and S.A.) independently reviewed each retrieved report. Discrepancies between the 2 reviewers were resolved by discussion and consensus. The final results were reviewed by the senior investigators (C.C. and T.D.Y.).

\section{RESULTS}

\section{Quantity and Quality of Studies}

Using the predefined search strategy, 161 references were retrieved for the initial screening, as summarized in the Preferred Reporting Items for Systematic Reviews and Meta-Analysis chart in Figure 1. After applying the predetermined selection criteria, 8 studies remained for analysis and inclusion in the present review. ${ }^{4-11}$ Of these, 4 studies had included data collected from the PARTNER trials ${ }^{4,5,7,10}$ and 4 had included registry data or published data review. ${ }^{6,8,9,11}$ Six studies described model-based evaluations performed in the context of different international healthcare systems. ${ }^{4-8,11}$ Of these, 2 had compared the cost-effectiveness of TAVI against medical management for patients with severe AS deemed to be inoperable, ${ }^{5,6}$ and the remaining 4 studies compared TAVI with medical treatment and AVR. ${ }^{4,7,8,11}$ Two studies had used retrospective clinical trial data without economic modeling. ${ }^{9,10}$ Osnabrugge and colleagues ${ }^{9}$ reported a propensity-matched retrospective analysis comparing the costs of TAVI and AVR among "intermediate surgical risk" patients. Reynolds and colleagues ${ }^{10}$ reported a prospective analysis of the PARTNER A study comparing the costs of TAVI and AVR during a 12-month period.

The model-based evaluations used different methods to estimate the future costs and outcomes of the procedures (Table 1). A Markov model or a similar statistical technique was used for the cost projections, and the probabilities of transitioning between cycles in the model were derived from the PARTNER study, ${ }^{5}$ registry data, ${ }^{8,11}$ or published data review. ${ }^{4,6,7}$ The total expense of TAVI, AVR, and medical management calculated using each model included the costs of the procedure, initial hospitalization, perioperative and long-term complications, repeat hospitalizations, physician fees, and drug costs. These costs were derived using government data, hospital billing data, or data collected from the PARTNER studies. ${ }^{2,12}$ The time horizons of all studies varied from 12 months to lifetime. The selection of this period was determined from the outcomes of the PARTNER A trial, which did not demonstrate any significant changes in mortality after 1 year. In addition, only 1 study presented data on the costs of preoperative investigations specific to TAVI, ${ }^{9}$ and the cost-effectiveness of performing concomitant cardiac surgery with AVR was not assessed. The quality of life was estimated using published utility weights, ${ }^{8,11}$ the results of the EuroQOL 5 dimensions (EQ-5D) questionnaire, ${ }^{4,5,10}$ or a New York Heart Association class transformation approach. ${ }^{4,6,7}$ The rate of annual discounting ranged from $1.5 \%$ to $5.0 \%$. All studies included a sensitivity analysis in which various hypothetical parameters were removed, applied, or modified to assess the stability of the results. Examples included the cost of the TAVI valve, ${ }^{4-6}$ hospitalization costs, ${ }^{6,9,10}$ and the rate of perioperative ${ }^{6,8}$ and long-term complications. ${ }^{7,8,11}$ Probabilistic sensitivity analyses were included in 6 of the 8 studies in the present systematic review. ${ }^{4-7,10,11}$

\section{Cost-Effectiveness of TAVI Versus Medical Therapy}

ICER has been the most commonly used economic parameter in determining the economic efficiency of a novel therapeutic procedure, and it was reported in all comparative studies identified in the present systematic review. $^{4-11}$ The ICER of 1 treatment compared with another has been defined as the cost required to gain 1 additional quality-adjusted life year (QALY). ${ }^{13}$ If a treatment produces an improvement in the QALYs gained at less expense, it would be considered economically dominant. The ICER thresholds of acceptability vary among countries and are not rigid. 


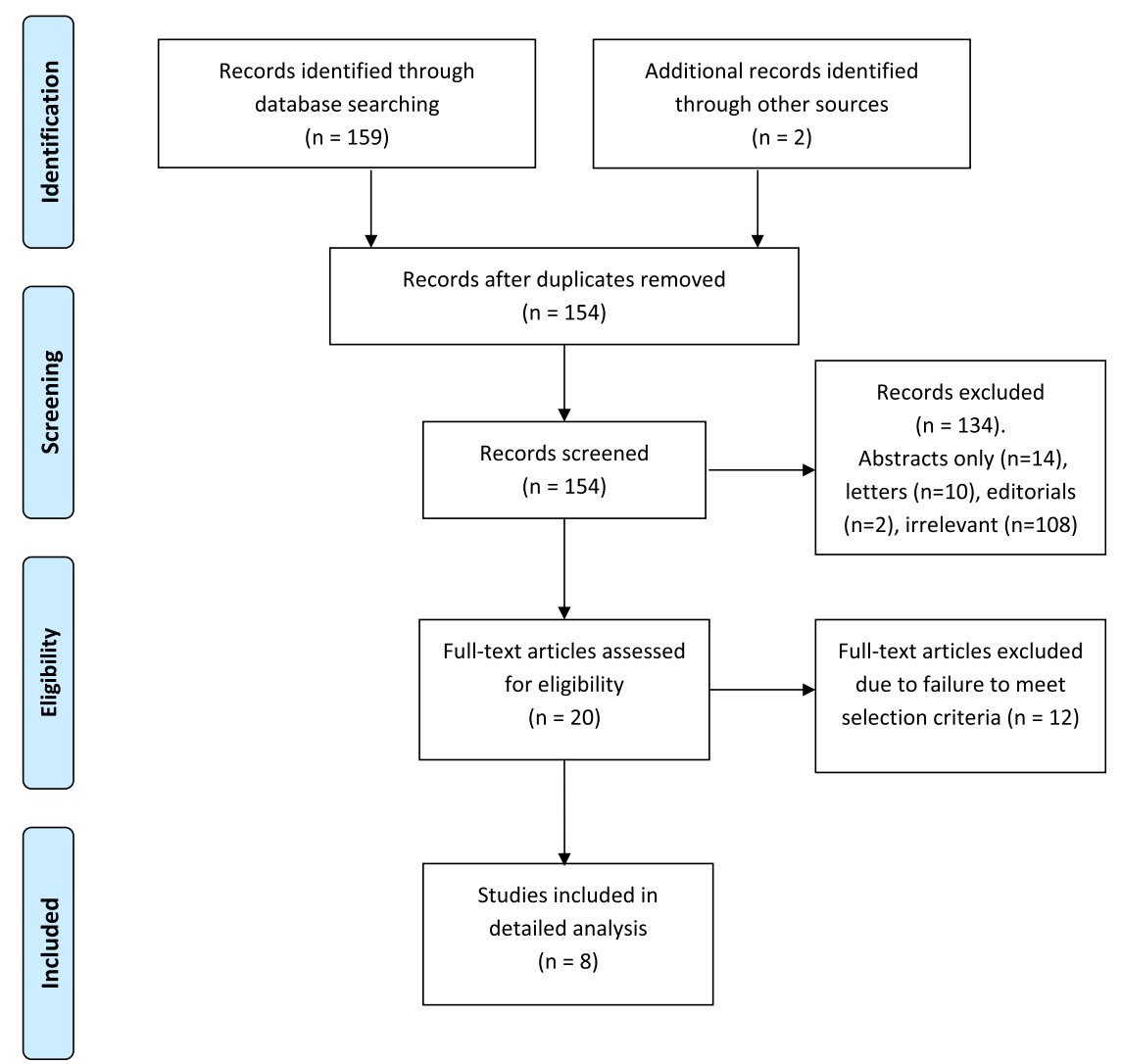

FIGURE 1. Preferred reporting items for systematic reviews and meta-analysis flow diagram summarizing the search strategy.

The projected costs of TAVI were consistently greater than medical therapy; however, TAVI was shown to improve the quality of life by 0.60 to 1.56 QALYs. $^{4-7}$ The ICER values ranged from US $\$ 26,302$ to $\$ 61,889$ per QALY gained (PQG; Table 2). Neyt and colleagues ${ }^{4}$ found the ICER to be approximately $€ 10,000$ (US $\$ 13,043$ ) less in a subgroup of "anatomically" inoperable patients compared with "medically" inoperable patients. The probabilistic sensitivity analyses demonstrated a wide variation in the results, as determined by the willingness-to-pay

TABLE 1. Summary of study characteristics comparing costs after TAVI and AVR or medical therapy

\begin{tabular}{|c|c|c|c|c|c|c|c|}
\hline Investigator & Year & Country & Model type & $\begin{array}{c}\text { Comparison } \\
\text { against TAVI }\end{array}$ & $\begin{array}{l}\text { TAVI population } \\
\text { group }\end{array}$ & $\begin{array}{l}\text { Simulations } \\
\text { or patients (n) }\end{array}$ & Time horizon \\
\hline Neyt et $\mathrm{al}^{4}$ & 2012 & Belgium & Single Markov model & MT and AVR & $\begin{array}{l}\text { PARTNER A and } \\
\text { B cohorts }\end{array}$ & 1000 & $\begin{array}{l}12 \text { mo for high-risk; } \\
\text { lifetime for } \\
\text { inoperable }\end{array}$ \\
\hline Reynolds et $\mathrm{al}^{5}$ & 2012 & US & Parametric survival model & MT only & PARTNER B cohort & 358 & Lifetime \\
\hline Watt et $\mathrm{al}^{6}$ & 2012 & UK & Double Markov models & MT only & PARTNER B cohort & 1000 & Lifetime \\
\hline Doble et $\mathrm{al}^{7}$ & 2012 & Canada & $\begin{array}{l}\text { Decision tree for short } \\
\text { term and Markov model } \\
\text { for long term }\end{array}$ & MT and AVR & $\begin{array}{l}\text { PARTNER A and } \\
\text { B cohorts }\end{array}$ & NR & $20 \mathrm{y}$ \\
\hline $\mathrm{Gada}_{\mathrm{e}} \mathrm{al}^{8}$ & 2012 & US & Single Markov model & $\begin{array}{r}\text { MT and AVR } \\
\text { (TF-TAVI) }\end{array}$ & $\begin{array}{l}\text { Registry data and } \\
\text { PARTNER A cohort }\end{array}$ & 10,000 & Lifetime \\
\hline Osnabrugge et $\mathrm{al}^{9}$ & 2012 & $\begin{array}{l}\text { The } \\
\text { Netherlands }\end{array}$ & No projection model used & AVR only & $\begin{array}{l}\text { Intermediate surgical } \\
\text { risk patients }\end{array}$ & $\begin{array}{l}84 \text { matched } \\
\text { patients }\end{array}$ & $12 \mathrm{mo}$ \\
\hline Reynolds et al ${ }^{10}$ & 2012 & US & No projection model used & AVR only & PARTNER A cohort & $\begin{array}{r}340 \text { TAVI } \\
307 \text { AVR }\end{array}$ & $12 \mathrm{mo}$ \\
\hline Gada et $\mathrm{al}^{11}$ & 2012 & US & Single Markov model & $\begin{array}{r}\text { MT and AVR } \\
\text { (TA-TAVI) }\end{array}$ & Registry data & 10,000 & Lifetime \\
\hline
\end{tabular}

TAVI, Transcatheter aortic valve implantation; $A V R$, aortic valve replacement; $M T$, medical therapy; PARTNER, Placement of Aortic Transcatheter Valve trial; $N R$, not reported; $T F$, transfemoral; $T A$, transapical. 
TABLE 2. Projected raw costs and incremental cost-effectiveness ratio for transcatheter aortic valve implantation versus medical therapy

\begin{tabular}{|c|c|c|c|c|c|c|c|c|}
\hline \multirow[b]{2}{*}{ Investigator } & \multirow{2}{*}{$\begin{array}{c}\text { QALYs } \\
\text { gained by TAVI }\end{array}$} & \multicolumn{2}{|c|}{ Projected mean raw cost } & \multirow{2}{*}{$\begin{array}{c}\text { Discounting } \\
\text { rate }(\%) \\
\end{array}$} & \multirow{2}{*}{$\begin{array}{c}\text { ICER (local } \\
\text { currency PQG) }\end{array}$} & \multirow{2}{*}{$\begin{array}{c}\text { ICER } \\
(\$ \mathbf{U S ~ P Q G ) *}\end{array}$} & \multirow{2}{*}{$\begin{array}{l}\text { WTPT used } \\
\text { (\$US PQG)* }^{*}\end{array}$} & \multirow{2}{*}{$\begin{array}{c}\text { Probability of } \\
\text { cost-effectiveness }\end{array}$} \\
\hline & & TAVI & MT & & & & & \\
\hline \multirow[t]{2}{*}{ Neyt et $\mathrm{al}^{4}$} & 1.30 & EUR 43,571 & EUR 3,170 & 3.0 & EUR 44,900 & 58,567 & 47,141 & 0.37 \\
\hline & & & & & & & 31,427 & 0.09 \\
\hline \multirow[t]{2}{*}{ Reynolds et $\mathrm{al}^{5}$} & 1.30 & USD 149,740 & USD 69,903 & 3.0 & USD 61,889 & 61,889 & 50,000 & 0.03 \\
\hline & & & & & & & 100,000 & 1.00 \\
\hline Watt et $\mathrm{al}^{6}$ & 1.56 & GBP 30,200 & GBP 5,000 & 3.5 & GBP 16,200 & 26,302 & 31,439 & 1.00 \\
\hline Doble et $\mathrm{al}^{7}$ & 0.60 & CAD 88,991 & CAD 57,963 & 5.0 & CAD 51,324 & 52,628 & 48,672 & 0.441 \\
\hline Gada et ${ }^{8}$ & NR & USD 59,503 & NR & 5.0 & USD 39,964 & 39,964 & 100,000 & NR \\
\hline Gada et $\mathrm{l}^{11}$ & NR & USD 56,730 & NR & 5.0 & USD 44,384 & 44,384 & 100,000 & NR \\
\hline
\end{tabular}

QALY, Quality-adjusted life-year; TAVI, transcatheter aortic valve implantation; $M T$, medical therapy; ICER, incremental cost-effectiveness ratio; WTPT, willingness-to-pay threshold; $P Q G$, per quality-adjusted life year gained; EUR, Euros; USD, US dollars; GBP, British pounds; $C A D$, Canadian dollars. *Converted to US dollars using exchange rates from www.xe.com, September 19, 2012.

threshold (WTPT). The probability of TAVI being cost-effective compared with medical therapy ranged from 0.03 to 1.00 . Reynolds and colleagues ${ }^{10}$ found the probability of TAVI being cost-effective at a WTPT of US $\$ 50,000$ of 0.03 . However, at a WTPT of US $\$ 100,000$, this probability increased to $1.00 .^{5}$

\section{Cost-Effectiveness of TAVI Versus AVR}

TAVI was reported to be more costly than AVR in all studies, ${ }^{4,7-11}$ apart from the transfemoral TAVI subgroup analyzed by Reynolds and colleagues. ${ }^{10}$ The number of QALYs gained by TAVI compared with AVR in high-risk surgical candidates ranged from -0.102 to 0.068 . $^{4,7-11}$ Three studies reported TAVI to be economically dominated by AVR. ${ }^{7,10,11}$ Of these 3 analyses, 2 were limited to transapical TAVI. ${ }^{10,11}$ In contrast, Reynolds and colleagues $^{10}$ found that TAVI using the transfemoral approach was economically dominant compared with AVR.${ }^{10}$ In the other analyses that did not establish economic dominance for either treatment modality, marked heterogeneity was present for the reported ICER values for TAVI versus AVR, ranging from US $\$ 32,000$ to \$975,697 (Table 3). ${ }^{4,9,1}$

The retrospective 12-month observational study performed by Osnabrugge and colleagues ${ }^{9}$ demonstrated an incremental cost of $€ 10,706$ (US $\$ 13,669$ ), favoring AVR. ${ }^{9}$ Because no quality of life data were collected, a figure of 0.068 QALYs gained, as quoted by the PARTNER study, was used to calculate the ICER for that study. In their analysis of transfemoral TAVI, Gada and colleagues ${ }^{8}$ performed multiple analyses using 3 separate sets of data. These included an index case based on registry data, an analysis based on the PARTNER A study, and a third analysis that combined the costs reported in the

TABLE 3. Projected raw costs of incremental cost-effectiveness ratio of transcatheter aortic valve implantation versus surgical aortic valve replacement

\begin{tabular}{|c|c|c|c|c|c|c|c|c|}
\hline \multirow[b]{2}{*}{ Investigator } & \multirow{2}{*}{$\begin{array}{c}\text { QALYs gained } \\
\text { by TAVI } \\
\end{array}$} & \multicolumn{2}{|c|}{ Projected mean raw cost } & \multirow{2}{*}{$\begin{array}{c}\text { Discounting } \\
\text { rate }(\%) \\
\end{array}$} & \multirow{2}{*}{$\begin{array}{c}\text { ICER (local } \\
\text { currency PQG) }\end{array}$} & \multirow{2}{*}{$\begin{array}{c}\text { ICER } \\
(\$ \text { US PQG)* }\end{array}$} & \multirow{2}{*}{$\begin{array}{c}\text { WTPT } \\
\text { (\$US PQG)* }^{*}\end{array}$} & \multirow{2}{*}{$\begin{array}{c}\text { Probability of } \\
\text { cost-effectiveness }\end{array}$} \\
\hline & & TAVI & AVR & & & & & \\
\hline Neyt et $\mathrm{al}^{4}$ & 0.03 & EUR 43,571 & EUR 23,749 & 3.0 & EUR 750,000 & 975,697 & 47,141 & NR \\
\hline Doble et $\mathrm{al}^{7}$ & -0.102 & CAD 85,755 & CAD 74,602 & 5.0 & Dominated by AVR & NA & 48,672 & 0.116 \\
\hline Gada et $\mathrm{al}^{8}$ & $\begin{array}{c}0.06 \\
\text { (reference case) }\end{array}$ & USD 59,503 & USD 56,339 & 5.0 & USD 52,773 & 52,773 & 100,000 & NR \\
\hline $\mathrm{Gada}_{\text {et }} \mathrm{al}^{8}$ & $\begin{array}{c}0.01 \text { (PARTNER } \\
\text { scenario) }\end{array}$ & USD 85,513 & USD 82,989 & 5.0 & USD 252,400 & 252,400 & 100,000 & NR \\
\hline $\mathrm{Gada}$ et $\mathrm{al}^{8}$ & 0.06 (combined) & USD 81,446 & USD 79,526 & 5.0 & USD 32,000 & 32,000 & 100,000 & NR \\
\hline Osnabrugge et $\mathrm{al}^{9}$ & $0.068 \dagger$ & EUR 46,217 & EUR 35,511 & NA & EUR 157,441 & 204,819 & NR & NR \\
\hline Reynolds et al $^{10}$ & $\begin{array}{c}0.027 \text { (TF- and } \\
\text { TA-TAVI) }\end{array}$ & USD 100,504 & USD 98,434 & NA & $\begin{array}{l}\text { USD } 76,877 \\
\text { (TF- and TA-TAVI) }\end{array}$ & 76,877 & 50,000 & 0.438 \\
\hline Reynolds et $\mathrm{al}^{10}$ & 0.068 (TF-TAVI) & USD 96,743 & USD 97,992 & NA & $\begin{array}{l}\text { AVR dominated by } \\
\text { TF-TAVI }\end{array}$ & NA & 50,000 & 0.709 \\
\hline Reynolds et al $^{10}$ & -0.070 (TA-TAVI) & USD 109,405 & USD 99,499 & NA & $\begin{array}{l}\text { TA-TAVI dominated } \\
\text { by AVR }\end{array}$ & NA & 50,000 & 0.071 \\
\hline 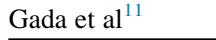 & -0.04 (TA-TAVI) & USD 56,730 & USD 56,630 & 5.0 & Dominated by AVR & NA & 100,000 & 0.47 \\
\hline
\end{tabular}

QALY, Quality-adjusted life-year; TAVI, transcatheter aortic valve implantation; $A V R$, aortic valve replacement; ICER, incremental cost-effectiveness ratio; $E U R$, euros; $N R$, not reported; $C A D$, Canadian dollars; NA, not applicable; USD, US dollars; PARTNER, Placement of Aortic Transcatheter Valve trial; $T F$, transfemoral; $T A$, transapical. *Converted to USD using exchange rates from www.xe.com, September 19, 2012. $†$ The study did not evaluate quality of life, and a value of 0.06 was used to calculate the ICER. 
PARTNER A study with the outcomes of the index case. ${ }^{2,8}$ The ICER of the PARTNER scenario analysis far exceeded that of the index case and combined analysis (Table 3).

Sensitivity analyses were performed in all studies to identify the potential parameters that might significantly influence the cost-effectiveness of TAVI. Gada and colleagues $^{11}$ noted that a reduction in the 12-month mortality rate of transapical TAVI from $25.28 \%$ to $24 \%$ would significantly alter the analysis, rendering TAVI economically dominant. The probabilistic sensitivity analyses demonstrated that the probability of TAVI being cost-effective compared with AVR ranged from 0.071 to 0.709 .

\section{DISCUSSION}

The present study represents the first systematic review to assess the cost-effectiveness of TAVI compared with other treatment modalities for patients with symptomatic AS. Separate comparisons were made for TAVI versus medical therapy in inoperable patients and TAVI versus surgical AVR in high-risk operable patients using the ICER and the probability of cost-effectiveness. Nation-specific ICER thresholds of acceptability have varied widely, depending on the financial structure and revenue patterns of the healthcare system in question. ${ }^{14}$ It has been suggested that for an intervention to be considered cost-effective, its ICER value should not exceed 3 times that of the nation's per capita gross domestic product, although these thresholds have generally been used as guidelines. ${ }^{15}$ In the US healthcare system, no definite ICER threshold for acceptability has been established. However, costs less than US $\$ 50,000$ PQG have generally been accepted as cost-effective, and costs of US $\$ 50,000$ to $\$ 100,000$ PQG have been considered to be within an intermediate zone of uncertainty. ${ }^{16}$ Such thresholds have been used for guidance only and have rarely been the sole discriminator of cost-effectiveness within an economic system.

The findings of the present study have demonstrated that the projected ICER of TAVI compared with medical therapy for inoperable patients ranged from \$26,302 PQG to $\$ 61,889$ PQG. $^{4-7}$ The probability of cost-effectiveness largely depended on the WTPT used in the individual studies. This was demonstrated by Reynolds and colleagues, ${ }^{5}$ who reported a probability of 0.03 to 1.00 for the cost-effectiveness of TAVI compared with medical therapy, depending on the proposed WTPT. However, even after modification of the model parameters within the sensitivity analyses, TAVI remained economically attractive compared with the medical treatment at the US \$100,000 PQG threshold. The cost-effectiveness of TAVI compared with medical therapy would likely be greater for patients deemed inoperable for anatomic reasons, such as a porcelain aorta, chest wall deformity, or previous thoracic radiotherapy. These patients will be more likely to experience favorable outcomes after TAVI procedures because of having fewer medical comorbidities. ${ }^{4}$ Overall, despite the much greater initial costs, the improvement in the quality and longevity of life suggests that TAVI might be an efficacious and cost-effective alternative to medical therapy for symptomatic inoperable patients.

However, the data from the present review did not conclusively demonstrate that TAVI is incrementally cost-effective compared with AVR for high-risk surgical candidates, because of the wide variability of ICER values and probabilities of economic acceptability reported. Of the 9 analyses, 6 reported an ICER value that would have been deemed unacceptable using a US \$100,000 PQG threshold ${ }^{4,7,8,10,11}$ and 7 would have been deemed unacceptable using a US \$50,000 PQG threshold. ${ }^{4,71}$ Only 1 sensitivity analysis demonstrated a probability of economic acceptability $>0.5 .{ }^{10}$ Four analyses suggested TAVI to be a cost-effective alternative to AVR using a WTPT of US $\$ 100,000$ PQG. These were the analyses involving transfemoral TAVI using registry data published by Gada and colleagues ${ }^{8}$ and Reynolds and colleagues, ${ }^{10}$ both of which were based in the United States. The cost differences between the transfemoral and transapical approaches to TAVI were only analyzed in 1 study, which suggested significant differences in expense favoring the transfemoral approach, possibly owing to differences in comorbidities. ${ }^{10,17}$

A number of factors could have contributed to the wide variations in the results among the individual analyses. These included differing materials costs, hospitalization costs, complication rates, and the nature and duration of the mathematical projection model used. For example, in the United States, the total costs of TAVI and AVR were generally similar, because the more costly device- and procedure-related expenses for TAVI were offset by the comparatively greater costs of hospitalization after AVR. The costs of hospitalization in the United States are $\geq 6$ times greater than those in European countries. ${ }^{18}$ Another significant difference between the treatment approaches is the cost of the valvular device. The Edwards-SAPIEN valve (Edwards Lifesciences, Irvine, Calif) has a reported cost of US $\$ 23,000$ to $\$ 30,000$. $^{5,10}$ This was significantly greater than the cost of the typical bioprosthetic valve used in AVR at approximately US $\$ 3500 .^{9}$ Of the studies that compared TAVI with AVR, only 1 examined a reduction in the TAVI valve cost in the sensitivity analysis. In that analysis, the ICER remained unacceptably high. ${ }^{4}$ Adding to the observed variability was the heterogeneous sources of data used for the clinical outcomes, costs, and quality of life. Three studies used registry data in their analysis, ${ }^{8,9,11}$ and the remainder used data from the PARTNER trials ${ }^{4,5,7,10}$ or published data review. ${ }^{6}$ Gada and colleagues ${ }^{8}$ found the ICER value calculated using data from the PARTNER trial far exceeded 
that calculated from registry data, suggesting that the outcomes and costs in the standard clinical setting might differ from that of a randomized control trial. This might have partly resulted from the different baseline characteristics of the patients included in registries and randomized trials.

It should be acknowledged that all the model-based evaluations included in the present systematic review were based on the PARTNER trials and limited to the Edwards-SAPIEN valve (Edwards Lifesciences), with only 1 exception. ${ }^{9}$ Other randomized controlled trials comparing TAVI and AVR also exist in the published data, including the STACCATO trial, which was prematurely terminated owing to excessive morbidity and mortality in the TAVI group. ${ }^{19}$ The long-term efficacy of TAVI bioprostheses remains largely unknown, and potential complications such as valvular insufficiency beyond the existing follow-up periods could result in additional hospitalizations and increased costs greater than the present estimates. A cost analysis of the CoreValve (Medtronic, Minneapolis, Minn) might be possible in the near future after the completion of randomized controlled trials currently underway. ${ }^{20}$ The existence of a single completed randomized controlled trial in the published data has limited the available comparative morbidity and mortality outcomes used in cost projection analyses.

\section{CONCLUSIONS}

The present systematic review showed that TAVI is potentially a cost-effective alternative to medical therapy for inoperable patients with symptomatic AS in selected healthcare settings. Although the raw costs of TAVI are greater, the procedure has been associated with a significant gain in quality-adjusted life years compared with medical management. However, in high-risk but operable surgical candidates, current data suggest that TAVI might not be a viable economic alternative to AVR. This could possibly change in the near future, as TAVI operators obtain more procedural experience and reduce perioperative morbidity and mortality to improve the cost-effectiveness for TAVI. In addition, it has been anticipated that advances in technology and material cost discounts will further decrease the ICER of TAVI. Nation-specific cost-effectiveness evaluations are recommended, because the threshold for economic acceptability depends on a nation's societal utility values and revenue patterns.

\section{References}

1. Ben-Dor I, Pichard A, Gonzalez M, Weissman G, Li Y, Goldstein S, et al. Correlates and causes of death in patients with severe symptomatic aortic stenosis who are not eligible to participate in a clinical trial of transcatheter aortic valve implantation. Circulation. 2010;122:S37-42.

2. Smith C, Leon M, Mack M, Miller M, Moses J, Svensson L, et al. Transcatheter versus surgical aortic-valve replacement in high-risk patients. $N$ Engl J Med. 2011;364:2187-98.

3. Van Brabandt H, Neyt M, Hulstaert F. Transcatheter aortic valve implantation (TAVI): risky and costly. BMJ. 2012;345:e4710.

4. Neyt M, Van Brabandt H, Devriese S, Van De Sande S. A cost-utility analysis of transcatheter aortic valve implantation in Belgium: focusing on a well-defined and identifiable population. BMJ Open. 2012;2:e001032.

5. Reynolds M, Magnuson E, Wang K, Lei Y, Vilain K, Walczak J, et al. Cost-effectiveness of transcatheter aortic valve replacement compared with standard care among inoperable patients with severe aortic stenosis. Circulation. 2012;125:1102-9.

6. Watt M, Mealing S, Eaton J, Piazza N, Moat N, Brasseur P, et al. Cost-effectiveness of transcatheter aortic valve replacement in patients ineligible for conventional aortic valve replacement. Heart. 2012;98: 370-6.

7. Doble B, Blackhouse G, Goeree R, Xie F. Cost-effectiveness of the Edwards SAPIEN transcatheter heart valve compared with standard management and surgical aortic valve replacement in patients with severe symptomatic aortic stenosis: a Canadian perspective. J Thorac Cardiovasc Surg. 2013;146: 52-60.e3.

8. Gada H, Kapadia S, Tuzcu E, Svensson L, Marwick T. Markov model for selection of aortic valve replacement versus transcatheter aortic valve implantation (without replacement) in high-risk patients. Am J Cardiol. 2012; 109:1326-33.

9. Osnabrugge R, Head S, Genders T, Mieghem NV, De Jaegere P, van der Boon R, et al. Costs of transcatheter versus surgical aortic valve replacement in intermediate risk patients. Ann Thorac Surg. 2012;94:1954-60.

10. Reynolds M, Magnusson E, Lei Y, Wang K, Vilain K, Li H, et al. Cost-effectiveness of transcatheter aortic valve replacement compared with surgical aortic valve replacement in high-risk patients with severe aortic stenosis. J Am Coll Cardiol. 2012;60:2683-90.

11. Gada H, Agarwal S, Marwick T. Perspective on the cost-effectiveness of transapical aortic valve implantation in high-risk patients: outcomes of a decision analytic model. Ann Cardiothorac Surg. 2012;1:145-55.

12. Kodali S, Williams M, Smith C, Svensson L, Webb J, Makkar R, et al. Two-year outcomes after transcatheter or surgical aortic-valve replacement. $N$ Engl J Med. 2012;366:1686-95.

13. Shaw L, Eisenstein E, Hachamovitch R, Heller G, Miller D. A primer of biostatistic and economic methods for diagnostic and prognostic modeling in nuclear cardiology: part II. J Nucl Cardiol. 1997;4:52-60.

14. Belgian Health Care Knowledge Centre. Threshold Values for CostEffectiveness in Health Care. Brussels: Belgian Health Care Knowledge Centre; 2008.

15. World Health Organization. Cost effectiveness ratio thresholds. Available at: http://www.who.int/entity/choice/costs/CER_thresholds_regions.xls. Accessed December 1, 2012.

16. Hlatky M, Simmons C. Cost-effectiveness of transcatheter aortic valve replacement. Circulation. 2012;125:1076-7.

17. Cao C, Ang S, Indraratna $\mathrm{P}$, Manganas $\mathrm{C}$, Bannon $\mathrm{P}$, Black D, et al. Systematic review and meta-analysis of transcatheter aortic valve implantation versus surgical aortic valve replacement for patients with severe aortic stenosis. Ann Cardiothorac Surg. 2013;2:10-23.

18. International Federation of Health Plans. Comparative Price Report 2011. Available at: http://www.ifhp.com/documents/2011iFHPPriceReportGraphs_ version3.pdf. Accessed December 1, 2012.

19. Neilsen H, Klaaborg K, Nissen H, Terp K, Mortensen P, Kjeldsen B, et al. A prospective, randomised trial of transapical transcatheter aortic valve implantation vs. surgical aortic valve replacement in operable elderly patients with aortic stenosis: the STACCATO trial. Eurointervention. 2012; 8:383-9.

20. Medtronic CoreValve. CoreValve U.S. Pivotal Trial 2011. Available at: http:// www.medtronic.com/aorticstenosistrial/trial.html. Accessed November 15, 2012. 